\title{
Binding of Free Bile Acids by Cells of Yogurt Starter Culture Bacteria ${ }^{1}$
}

\author{
R. M. Pigeon, ${ }^{2}$ E. P. Cuesta, and S. E. Gilliland $†$ \\ Department of Animal Science \& Food and Agricultural Products Center \\ Oklahoma State University, Stillwater 74078
}

\begin{abstract}
Several strains of Lactobacillus delbrueckii ssp. bulgaricus and Streptococcus thermophilus, which produced exocellular polysaccharides (EPS), varied in the amount produced. The streptococci tended to produce the most EPS per milliliter of culture; however, when compared on the basis of amounts per $10^{7} \mathrm{cfu}$, the lactobacilli produced the most. Lactobacillus delbrueckii ssp. bulgaricus strains Lb-18 and Lb-10442 and S. thermophilus St-143 produced significantly larger amounts per $10^{7} \mathrm{cfu}$ than did other strains tested. These three cultures plus two strains of the streptococci that produced the greatest amounts of EPS per $\mathrm{ml}$ of culture were tested for the ability to bind bile acids from laboratory media. The two cultures of $L$. delbrueckii ssp. bulgaricus (Lb-18 and Lb-10442) bound significantly higher amounts of cholic acid than did the three strains of streptococci. These two cultures of lactobacilli bound up to $15.3 \%$ of the cholic acid present in laboratory media, up to $452 \mu \mathrm{g} / \mathrm{mg}$ of EPS and $2.9 \mu \mathrm{g} / 10^{7} \mathrm{cfu}$. None of the cultures tested in this study were able to bind the conjugated bile acid, glycocholic acid.
\end{abstract}

(Key words: bile salt, exocellular polysaccharide, Lactobacillus, Streptococcus)

Abbreviation key: EPS = exocellular polysaccharide, NDM $=$ nonfat dry milk.

\section{INTRODUCTION}

Elevated levels of serum cholesterol can lead to complications such as stroke and coronary heart disease (Pekkanen et al., 1990). Certain lactic acid bacteria such as lactobacilli have the potential to aid in the control of serum cholesterol levels. Mann and Spoerry (1974) first demonstrated that milk fermented with lactobacilli might exhibit hypocholesterolemic effects in

Received December 15, 2001.

Accepted March 8, 2002.

Corresponding author: S. Gilliland; e-mail: seg@okstate.edu.

${ }^{1}$ Approved for publication by the Director, Oklahoma Agricultural Experiment Station. This project was supported under Project H2293.

${ }^{2}$ Current address: McKee Foods Corp., Gentry, AR. humans. Other researchers have since found that some lactobacilli exhibit a cholesterol-lowering ability in man (Anderson and Gilliland, 1999) and animals (Grunewald, 1982; Gilliland et al., 1985).

Several researchers have attempted to elucidate the mechanism involved in the hypocholesterolemic action of these strains of lactic acid bacteria. One proposed mechanism is assimilation of cholesterol by the cells of Lactobacillus acidophilus during growth (Gilliland et al., 1985; Buck and Gilliland, 1994). Noh et al. (1997) demonstrated the ability of a strain of L. acidophilus to incorporate cholesterol from growth medium into cellular membranes during growth. Removal or assimilation of cholesterol by intestinal organisms in the small intestine could reduce the amount of cholesterol available for absorption from the intestine, thus exerting some control on serum cholesterol levels. Another plausible mechanism is deconjugation of bile acids by lactobacilli that produce the enzyme bile salt hydrolase. Deconjugated or free bile acids are more likely than are conjugated ones to be excreted from the body (Dietschy et al., 1966; Schiff et al., 1972). Thus, an increase in bile acid deconjugation in the intestines would continuously drain the cholesterol pool as more bile acids are synthesized. Many researchers have found bile salt hydrolase activity in strains of lactic acid bacteria, including $L$. acidophilus (Gilliland and Speck, 1977; Kobashi et al., 1978; Tannock, et al, 1989).

The exocellular polysaccharides produced by lactic acid bacteria are either excreted into the growth medium as free exocellular polysaccharides (EPS) or they adhere to the cell as capsular EPS (Sutherland, 1972). Due to the potential benefits of these bacteria to the quality of fermented dairy food products, several thermophilic and mesophilic lactic acid bacteria, and the polymers they produce, have been studied. Streptococcus thermophilus (Doco et al., 1990; Cerning et al., 1992), Lactobacillus delbrueckii ssp. bulgaricus (Bouzar et al., 1992; Grobben et al., 1995; Uemura et al., 1998.), other lactobacilli (Dunican and Seeley, 1965; Mozzi et al., 1994) and Bifidobacterium longum (Andaloussi et al., 1995) have been included in these studies. Most of these focused on the structure and characterization of the EPS. Very few have studied the potential health-promoting effects of EPS. Among these, Nakaj- 
ima et al. (1992) focused on the cholesterol-lowering activity of milk fermented with an EPS producing lactic acid bacteria. The consumption of this fermented milk significantly decreased serum cholesterol levels in rats, where as the consumption of milk fermented with a non-EPS producing strain did not. There is potential for these polymers to interfere with the absorption of cholesterol or of bile acids from the intestines by binding them and removing them from the body in a manner similar to that reported for plant-based polysaccharides or dietary fiber (Kritchevsky and Story, 1975).

The objective of this study was to determine whether different strains, $S$. thermophilus and $L$. delbrueckii ssp. bulgaricus, that produce capsular ESP have the ability to bind bile acids in vitro.

\section{MATERIALS AND METHODS}

\section{Source and Maintenance of Cultures}

The cultures used in this study were obtained from two sources. L. delbrueckii ssp. bulgaricus Lb-18 and Lb-10442, as well as $S$. thermophilus St-143 were obtained from Chris Hansen Inc. (Milwaukee, WI). Streptococcus thermophilus St-OSU1, St-OSU2, St-OSU3, L. delbrueckii ssp. bulgaricus Lb-OSU4 and Lb-OSU5 were all from the stock culture collection of the Food Microbiology Laboratory of the Food and Agricultural Products Center at Oklahoma State University. The cultures were maintained by subculturing weekly using $1 \%$ inocula in lactobacilli MRS broth made from individual ingredients according to the manufacturer's directions (Difco Laboratories, Detroit, MI), except that 4\% lactose was used in the place of glucose (MRSL). The inoculated broth was incubated for $18 \mathrm{~h}$ at $37^{\circ} \mathrm{C}$. The cultures were stored at $7^{\circ} \mathrm{C}$ between transfers. Stock cultures were stored in MRSL agar stabs (MRSL broth plus $1.5 \%$ agar). The cultures were subcultured at least three times immediately before experimentation. In addition, the cultures were subcultured using $1 \%$ inocula in sterile $10 \%$ reconstituted nonfat dry milk (NDM) at least three times before experimentation involving milk as the growth medium. The milk subcultures were incubated at $37^{\circ} \mathrm{C}$ for $18 \mathrm{~h}$ and stored at $7^{\circ} \mathrm{C}$ between transfers.

\section{Preparation of Milk for EPS Production}

The milk was prepared by reconstituting a commercial instantized NDM in deionized water at $10 \%$ (wt/ vol). For use in experiments involving the measurement of EPS production, the $10 \% \mathrm{NDM}$ was pasteurized at $80^{\circ} \mathrm{C}$ for $30 \mathrm{~min}$ and then refrigerated at $7^{\circ} \mathrm{C}$ until inoculation. It was prepared and used the same day.

\section{Measurement of Capsular EPS}

The measurement of capsular EPS material is complicated by its close association with the bacterial cells (Sutherland, 1972). The concentrations were measured based on the amount of carbohydrate expressed as glucose present in washed cell suspensions (Gilliland and Speck, 1974). The carbohydrate concentrations were determined by either a variation of the anthrone method (Gilliland and Speck, 1974) or the phenol-sulfuric method (Dubois et al., 1956), with glucose as the standard and the amount of EPS expressed as $\mu \mathrm{g}$ of glucose/ml of culture.

\section{Enumeration of Lactobacilli and Streptococci}

The numbers of lactobacilli and streptococci in the experimental samples were determined using the pour plate with overlay method (Vanderzant and Splittstoesser, 1992) on MRSL agar. Dilutions were prepared using $99-\mathrm{ml}$ volumes of a sterilized solution of $0.1 \%$ peptone (Difco Laboratories) and $0.01 \%$ silicone antifoam (Sigma Chemical Co.). Plates were incubated at $37^{\circ} \mathrm{C}$ for $48 \mathrm{~h}$, and colonies were counted with the aid of a Quebec colony counter (American Optical Co. Buffalo, NY).

\section{Initial Screening of Cultures for Capsular EPS Production}

The strains of S. thermophilus and L. delbrueckii ssp. bulgaricus were initially tested to determine the level of capsular EPS produced in 10\% reconstituted NDM. Volumes of $10 \mathrm{ml}$ of freshly pasteurized $10 \%$ NDM were inoculated with each of the eight cultures using $1 \%$ inocula and incubated at $45^{\circ} \mathrm{C}$ for $8 \mathrm{~h}$. The capsular EPS content was based on sugar content of the cells and was determined in a manner similar to that of Gilliland and Speck (1974). The milk proteins were solubilized by adding $1.1 \mathrm{ml}$ of $20 \%$ (wt/vol) sodium citrate to $5.5 \mathrm{ml}$ volumes of each culture, and then $4.4 \mathrm{ml}$ of deionized water was added, bringing the final concentration to $2 \%$ sodium citrate. The cells were collected by centrifugation at $12,000 \times g$ for $15 \mathrm{~min}$ at $0^{\circ} \mathrm{C}$. Each pellet was washed once with $11 \mathrm{ml}$ of cold deionized water and resuspended in $5.5 \mathrm{ml}$ of cold deionized water. The total sugar content of the cell suspension was determined by the anthrone method. The amount of capsular EPS was expressed as $\mu \mathrm{g}$ of glucose/ml of original culture. In addition, plate counts were determined by the pour plate method as described above. This allowed the amount of EPS per $10^{7} \mathrm{cfu}$ to be calculated and compared among strains. 


\section{Measurement of Bile Acids}

The quantification of free bile acid (cholic acid) was accomplished by the method described by Walker and Gilliland (1993). A standard curve was prepared using the sodium salt of cholic acid (Sigma Chemical Co.).

\section{Measurement of Bile Acid Binding}

To determine whether the strains were able to bind bile acids, presumably to the capsular EPS, an experiment was designed with cells grown in the MRSL broth. Bottles containing $75 \mathrm{ml}$ of MRSL were inoculated (1\%) with selected strains and incubated at $45^{\circ} \mathrm{C}$ for $8 \mathrm{~h}$. Following incubation, two $22.5-\mathrm{ml}$ volumes of each culture were transferred into sterile 50-ml Erlenmeyer flasks. To one, $2.5 \mathrm{ml}$ of a $15 \mathrm{mM}$ solution of cholic acid (sodium salt) was added, bringing the final concentration of bile acid to $1.5 \mathrm{mM}(646 \mu \mathrm{g} / \mathrm{ml})$. The second received similar $\mathrm{m} M$ concentration of the sodium salt of glycocholic acid. These samples were held in a $37^{\circ} \mathrm{C}$ shaker water bath, with gentle agitation for $2 \mathrm{~h}$ to allow contact between the cells and the bile acids.

Following the shaking step, the $\mathrm{pH}$ of each mixture was adjusted to 7.0 and the cells removed by centrifugation $\left(12,000 \times g\right.$ at $0^{\circ} \mathrm{C}$ for $\left.10 \mathrm{~min}\right)$. Any bound bile acid would by removed when the cells were removed. The supernatant fluids were assayed for bile salt using the colorimetric assay (Walker and Gilliland, 1993). An uninoculated control was included to permit a calculation of the amounts of bile salts removed (i.e., bound to the cells).

A portion of the initial broth culture was also analyzed for capsular EPS content using the same procedure as for the milk cultures, except that sodium citrate was not necessary to recover the cells from the broth culture. The phenol-sulfuric method was used to quantify the capsular EPS content of the cells. This information allowed calculations of the amount of bile acid bound per milligram of EPS present.

\section{Effect of Initial pH on the Bile Binding Assay}

Since the solubility of cholic acid decreases as the $\mathrm{pH}$ drops below 6.0, we evaluated the potential influence of acidity of broth on its recovery in our assay system. To test whether or not the $\mathrm{pH}$ of the broth cultures might have affected the removal of the bile acid, MRSL broth containing $1.5 \mathrm{~m} M$ cholic acid (sodium salt) was prepared and portions adjusted to the $\mathrm{pH} 6.5,6.0,5.0$, 4.0, 3.0, 2.0, and 1.0. The broth was held in a shaker water bath for $2 \mathrm{~h}$, adjusted to $\mathrm{pH} 7.0$, centrifuged $\left(12,000 \times g\right.$ at $0^{\circ} \mathrm{C}$ for $\left.10 \mathrm{~min}\right)$, and the supernatant was analyzed for cholic acid following the same procedure described in the previous section.
Table 1. Comparison of amounts of capsular exocellular polysaccharide (EPS) produced by strains of Lactobacillus delbrueckii ssp. bulgaricus and Streptococcus thermophilus grown in $10 \%$ nonfat dry milk.

\begin{tabular}{lllc}
\hline Culture $^{1}$ & $\mu \mathrm{g} / \mathrm{ml}^{2,4}$ & $\mathrm{cfu} / \mathrm{ml}$ & $\mu \mathrm{g} / 10^{7} \mathrm{cfu}^{3,4}$ \\
\hline St-OSU3 & $857^{\mathrm{a}}$ & $2.1 \times 10^{9}$ & $4.1^{\mathrm{c}}$ \\
St-OSU2 & $505^{\mathrm{b}}$ & $9.3 \times 10^{8}$ & $5.5^{\mathrm{c}}$ \\
St-OSU1 & $478^{\mathrm{b}}$ & $1.3 \times 10^{9}$ & $4.4^{\mathrm{c}}$ \\
Lb-OSU4 & $471^{\mathrm{b}}$ & $3.9 \times 10^{8}$ & $12.3^{\mathrm{c}}$ \\
Lb-OSU5 & $451^{\mathrm{b}}$ & $2.8 \times 10^{8}$ & $16.6^{\mathrm{c}}$ \\
Lb-10442 & $448^{\mathrm{b}}$ & $1.3 \times 10^{8}$ & $47.4^{\mathrm{b}}$ \\
St-143 & $439^{\mathrm{b}}$ & $9.6 \times 10^{7}$ & $47.0^{\mathrm{b}}$ \\
Lb-18 & $398^{\mathrm{b}}$ & $5.8 \times 10^{7}$ & $70.6^{\mathrm{a}}$ \\
\hline
\end{tabular}

${ }^{1} \mathrm{Lb}=$ Lactobacillus delbrueckii $\mathrm{ssp}$. bulgaricus $; \mathrm{St}=$ Streptococcus thermophilus.

${ }^{2}$ EPS is expressed as glucose $\mu \mathrm{g} / \mathrm{ml}$ of cell suspension isolated from 8-hour cultures grown at $45^{\circ} \mathrm{C}$.

${ }^{3} \mathrm{EPS}$ is expressed as glucose $\mu \mathrm{g} / 10^{7} \mathrm{cfu}$ in 8-hour cultures grown at $45^{\circ} \mathrm{C}$.

${ }^{4}$ Values are the means of three replications. Means with no common superscript letters differ significantly $(P<0.05)$.

\section{Statistical Analyses}

Experiments were conducted in triplicate. Each value was the mean of three independent trials. The EPS concentration and the degree of binding of the bile acids were analyzed as independent variables in each respective experiment. The analysis involved the analysis of variance procedure of JMPIN statistical software (Sall and Lehman, 1996). The means with significant differences were separated using the least significant difference method within the statistical software.

\section{RESULTS}

\section{Initial Screening of Cultures for Capsular Exopolysaccharide Production}

Significant differences $(P<0.05)$ were observed among the strains in the amounts of EPS produced per $10^{7} \mathrm{cfu}$ in milk (Table 1). When considering the amount of EPS in $\mu \mathrm{g} / \mathrm{ml}, S$. thermophilus St-OSU3 produced significantly $(P<0.05)$ more than all other strains of both species in the study. The others, which were not significantly different, produced from 398 to $505 \mu \mathrm{g} / \mathrm{ml}$. The degree of difference among cultures was greater when compared on the basis of $\mu \mathrm{g} / 10^{7} \mathrm{cfu}$. Lactobacillus delbrueckii ssp. bulgaricus Lb-18 produced $70.6 \mu \mathrm{g} / 10^{7}$ $\mathrm{cfu}$, which was significantly greater $(P<0.05)$ than other cultures tested. Strains St-143 and Lb-10442 followed, with 47.0 and $47.4 \mu \mathrm{g} / 10^{7} \mathrm{cfu}$, respectively. These amounts were significantly higher $(P<0.05)$ than the remaining five strains that produced 4.1 to $16.6 \mu \mathrm{g} / 10^{7}$ $\mathrm{cfu}$. Based on the amount of EPS produced per $10^{7}$ cfu, three cultures (Lb-18, Lb-10442, and St-143) were selected for further study. In addition, St-OSU3 and St-OSU1 were included to compare strains with low 
Table 2. Binding of cholic acid (sodium salt) by capsular exocellular polysaccharide produced by strains of Lactobacillus delbrueckii ssp. bulgaricus and Streptococcus thermophilus grown in MRS Broth containing $4 \%$ lactose as the source of carbohydrate.

\begin{tabular}{|c|c|c|c|c|}
\hline Culture $^{1}$ & $\%$ Bound $^{2,5}$ & $\begin{array}{l}\mu \mathrm{g} \text { cholic acid/ } \\
\mathrm{mg} \operatorname{EPS}^{3,5}\end{array}$ & $\begin{array}{l}\mu \mathrm{g} \text { EPS/ } \\
\mathrm{ml}\end{array}$ & $\begin{array}{l}\mu \mathrm{g} \text { cholic acid/ } \\
10^{7} \mathrm{cfu}^{4,5}\end{array}$ \\
\hline Lb-10442 & $15.3^{\mathrm{a}}$ & $422^{\mathrm{a}}$ & 152 & $2.9^{\mathrm{a}}$ \\
\hline Lb-18 & $8.2^{\mathrm{b}}$ & $452^{\mathrm{a}}$ & 76 & $1.1^{\mathrm{ab}}$ \\
\hline St-OSU1 & $4.2^{\mathrm{c}}$ & $224^{\mathrm{b}}$ & 75 & $0.6^{\mathrm{b}}$ \\
\hline St-143 & $1.5^{\mathrm{d}}$ & $86^{c}$ & 75 & $0.4^{\mathrm{b}}$ \\
\hline St-OSU3 & $0.6^{\mathrm{d}}$ & $56^{\mathrm{c}}$ & 54 & $0.2^{\mathrm{b}}$ \\
\hline
\end{tabular}

${ }^{1} \mathrm{Lb}=$ Lactobacillus delbrueckii $\mathrm{ssp}$. bulgaricus; $\mathrm{St}=$ Streptococcus thermophilus.

${ }^{2}$ Values are expressed as a binding \%, percentage of cholic acid removed by contact with cells from 8 hour cultures grown at $45^{\circ} \mathrm{C}$.

${ }^{3}$ Values are expressed as $\mu \mathrm{g}$ of cholic acid bound per mg of glucose (EPS).

${ }^{4}$ Values are $\mu$ g of cholic acid bound per $10^{7}$ colony forming units (cfu).

${ }^{5}$ Values are the means of three replications. Means within columns with no common superscript letters differ significantly $(\mathrm{P}<0.05)$.

production activity per colony-forming units to the more active strains.

\section{Measurement of Bile Acid Binding}

There were significant differences $(P<0.05)$ among the five strains with respect to the binding of cholic acid (Table 2). The degree of binding was measured as percentage of cholic bound and micrograms of cholic acid bound per milligram of EPS. Strain Lb-10442, which produced the most EPS, bound the greatest amount $(P<0.05)$ of bile acid measured at $15.3 \%$, which was nearly twice that of strain Lb-18, which bound $8.2 \%$. Culture St-OSU1 was able to remove $4.2 \%$, while the two remaining strains, St-143 and St-OSU3, were able to bind only minimal amounts. The latter two produced the least amount of EPS. When the results of the microgram of cholic acid bound per milligram of EPS were analyzed, very similar differences were observed. However, there was no difference $(P>0.05)$ between strain Lb-18 (452 $\mu \mathrm{g} / \mathrm{mg}$ of EPS) and Lb-10442 (422 mg/ $\mathrm{mg}$ of EPS). The strains of streptococci St-OSU1, St143 , and St-OSU3 bound significantly less $(P<0.05)$ than the two strains of lactobacilli with 224,86 , and $56 \mu \mathrm{g} / \mathrm{mg}$ of EPS, respectively. In addition, strain Lb10442 was able to bind $2.9 \mu \mathrm{g} / 10^{7} \mathrm{cfu}$, which was significantly higher than all the streptococci. Results from experiments to test for the binding of glycocholic acid indicated that none of the strains in this study would bind this conjugated bile acid (data not shown).

\section{Effect of Initial pH on the Bile Binding Assay}

To validate that sodium cholate was being associated with the bacterial cells and not just precipitating due to low $\mathrm{pH}$ of the cultures, an experiment was conducted to determine the effect of the $\mathrm{pH}$ on the removal of cholic acid from MRSL broth. The series of broth samples at various $\mathrm{pH}$ levels were treated and analyzed exactly as mentioned in the procedure to test the cultures for the ability to bind bile acids. After incubation for $2 \mathrm{~h}$ at $37^{\circ} \mathrm{C}$ in the broth at $\mathrm{pH} 6.5,6.0,5.0,4.0,3.0,2.0$, and 1.0 , then adjusting each to $\mathrm{pH} 7.0$ and centrifuging all the bile acid was recovered in the supernatant fluid. Thus, none was removed by exposure to low $\mathrm{pH}$ levels.

\section{DISCUSSION}

Some species of lactic acid bacteria, especially lactobacilli, have the potential to assist in the reduction of elevated serum cholesterol levels (Mann and Spoerry, 1974; Anderson and Gilliland, 1999). This beneficial action could involve their ability to assimilate cholesterol into cellular membranes (Noh et al., 1997) or to deconjugate bile acids (Gilliland and Speck, 1977; Kobashi et al., 1978; Tannock et al., 1989). Nakajima et al. (1992) found significant differences between serum cholesterol levels among rats consuming fermented milk made with cultures that do or do not produce exocellular polysaccharides. The authors theorized that the observed differences were due to reduced absorption in the intestines, of cholesterol or bile acids due to the exocellular polysaccharides. Due to the resistance of the polysaccharide to digestive enzymes and its waterholding capacity, they hypothesized that the bacterial polymer acted in a manner similar to a dietary fiber.

Other researchers have recognized the possible effects of intestinal organisms on the binding of bile acids or interference in their absorption from the intestine. Fecal sterol composition can be highly dependent upon the presence of bacteria in the intestines (Mott et al., 1973). Several possible factors were cited, including binding of bile acids by intestinal bacteria as being responsible for sterol balance in the body. Chikai et.al. 
(1987) studied the bile acid deconjugation ability of several species of bacteria. They found that an increase in bile acid deconjugation resulted in increased bile acid excretion. They speculated that adhesion of free bile acids, resulting from the deconjugation, to bacteria as well as dietary fibers might also contribute to the large amounts of bile acid excretion.

The results of this study indicate variation among cultures with respect to binding of cholic acid. The culture, L. delbrueckii ssp. bulgaricus, which produced the greatest amount of EPS, bound the most cholic acid per mg of EPS or $2.9 \mu \mathrm{g} / 10^{7}$ cfu from laboratory media. Since the cultures did not bind a conjugated bile acid (glycocholic acid), this indicates a possible action in enhancing increased excretion of free bile acids from the body after consumption of a fermented product made with such a culture. This could result in reduction of the cholesterol pool as cholesterol is used to synthesize more bile acid in the enterohepatic circulation to replace those excreted with the EPS via the feces.

In the screening portion of this study there were variable amounts of EPS produced in the milk by the cultures tested. The greatest amounts of EPS in $\mu \mathrm{g} / \mathrm{ml}$ were produced by the streptococci. However, the growth of the streptococci in milk resulted in much higher cell numbers in cfu/ml than the lactobacilli. As a measure of how much EPS per cell was produced, $\mu \mathrm{g}$ of EPS per $10^{7} \mathrm{cfu}$ was calculated. This allowed comparisons of strains on total amount produced, as well as the amount surrounding each cell. The lactobacilli produced the highest amounts per $10^{7} \mathrm{cfu}$. The five strains selected for further study exhibited variable production capabilities in both the total production and amount produced per cell. The amount of cholic acid bound was greatest for the cultures that produced the greatest amounts of EPS per $10^{7} \mathrm{cfu}$. However, glycocholic acid, a conjugated bile acid, was not bound by the cells of any of the five cultures.

Theoretically, consumption of yogurt manufactured with the cultures that produce EPS could bind free bile acids in the intestine, thus enhancing excretion of the bile acids via the feces. Figure 1 shows a comparison among the cultures in this study with regard to the amount of cholic acid that could theoretically be removed or bound when an 8-oz serving of the fermented milk or yogurt is consumed. These values are based on the populations and amounts of EPS that would be expected during growth of the cultures in milk. As with the other results, the most bile acid bound would be from the consumption of milk fermented with the $L$. delbrueckii ssp. bulgaricus strains Lb-10442 and Lb18. Up to $45 \mathrm{mg}$ of cholic acid could be removed by a serving yogurt made with Lb-10442. The theoretical amounts that could be bound by strains of streptococci

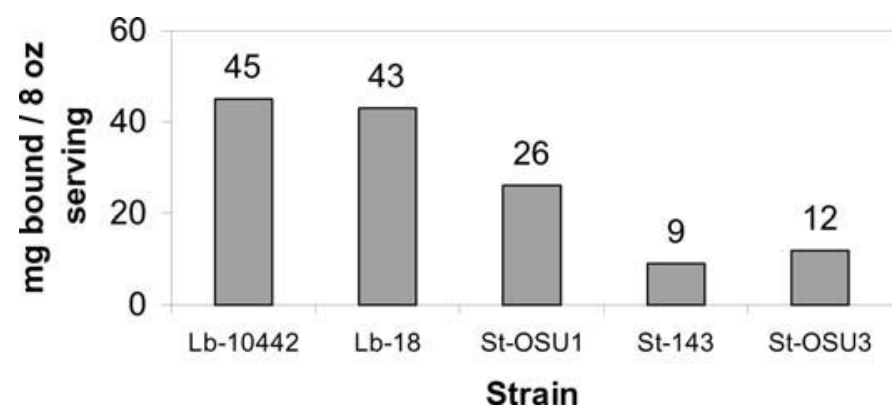

Figure 1. Comparison of the theoretical amounts of cholic acid that could be bound and removed from the body by consuming an 8 oz werving of cultured product containing each strain.

ranged from 9 to $26 \mathrm{mg}$ of cholic acid/8-oz serving. In addition, other experiments in our laboratory indicate that some of these cultures produce free EPS that are not associated with the cell (data not shown). This also may contribute to the total amount of bile acids that could be bound due consumption of the yogurt. In the present study, the strains of both species of cultures were examined individually. In the actual manufacture of traditional yogurt in which one or more strains of both species might be used, the amounts of EPS might vary which could influence the amounts of bile acids bound.

The binding of bile acids to capsular EPS may contribute to the development of a product containing a probiotic that uses a variety of mechanisms to control serum cholesterol levels. Strain or strains of starter cultures that have the ability to bind free bile acid could be used to produce a yogurt product in conjunction with a probiotic organism known to deconjugate bile acids. The strains in this study did not bind conjugated bile salts (sodium glycocholate). Increasing deconjugation of glycocholic due to the action of a deconjugating probiotic organism to release cholic acid would make more cholic available for binding and removal from the body. Even though the free bile acids are more likely to be excreted via the feces, the presence of an EPS that preferentially binds them over conjugated bile acids could enhance their excretion. Thus the combination of a probiotic culture such as $L$. acidophilus that deconjugates bile acids with selected strains of $L$. delbrueckii ssp. bulgaricus and $S$. thermophilus could be used to manufacture cultured yogurt that would have enhanced hypocholesterolemic activity. Such a product would be useful for hypercholesterolemic individuals.

\section{REFERENCES}

Andaloussi, S. A., H. Talbaoui, R. Marczak, and R. Bonaly. 1995. Isolation and characterization of exocellular polysaccharides pro- 
duced by Bifidobacterium longum. Appl. Microbiol. Biotechnol. 43:995-1000.

Anderson, J. W., and S. E. Gilliland. 1999. Effect of fermented milk (yogurt) containing Lactobacillus acidophilus L1 on serum cholesterol in hypercholesterolemic humans. J. Am. Coll. Nutr. 18:43-50.

Bouzar, F., J. Cerning, and M. Desmazeaud. 1996. Exocellular polysaccharide production in milk by Lactobacillus delbrueckii subsp. bulgaricus CNRZ 1187 and by two colonial variants. J. Dairy Sci. 79:205-211.

Buck, L. M., and S. E. Gilliland. 1994. Comparisons of freshly isolated strains of Lactobacillus acidophilus of human intestinal origin for ability to assimilate cholesterol during growth. J. Dairy Sci. 77:2925-2933.

Cerning, J., C. Bouillanne, M. Landon, and M. Desmazeaud. 1992. Isolation and characterization of exocellular polysaccharides from slime-forming mesophilic lactic acid bacteria. J. Dairy Sci. 75:692-699

Chikai, T., H. Nakao, and K. Uchida. 1987. Deconjugation of bile acids by human intestinal bacteria implanted in germ free rats. Lipids 22:669-671.

Dietschy, J. M., H. S. Salomon, and M. S. Siperstein. 1966. Bile acid metabolism. I. Studies on the mechanisms of intestinal transport. J. Clin. Invest. 45:832-846.

Doco, T., J. Wieruszeski, and B. Fournet. 1990. Structure of an exocellular polysaccharide produced by Streptococcus thermophilus. Carbohyd. Res. 198:313-321.

Dubois, M., K. A. Gilles, J. K. Hamilton, P. A. Rebers, and F. Smith. 1956. Colorimetric method for determination of sugars and related substances. Anal. Chem. 28:350-356.

Dunican, L. K., and H. W. Seeley. 1965. Extracellular polysaccharide synthesis by members of the genus Lactobacillus: Conditions of formation and accumulation. J. Gen. Microbiol. 40:297-308.

Gilliland, S. E., and M. L. Speck. 1974. Relationship of cellular components to the stability of concentrated lactic streptococcus cultures at $-17^{\circ} \mathrm{C}$. Appl. Microbiol. 27:793-796.

Gilliland, S. E., and M. L. Speck. 1977. Deconjugation of bile acids by intestinal lactobacilli. Appl. Environ. Microbiol. 33:15-18.

Gilliland, S. E., C. R. Nelson, and C. Maxwell. 1985. Assimilation of cholesterol by Lactobacillus acidophilus. Appl. Environ. Microbiol. 49:377-381.

Grobben, G. J., J. Sikkema, M. R. Smith, and J. A. M. de Bont. 1995. Production of extracellular polysaccharides by Lactobacillus delbrueckii subsp. bulgaricus NCFB 2772. J. Appl. Bacteriol. 79:103-107.

Grunewald, K. K. 1982. Serum cholesterol levels in rats fed skim milk fermented by Lactobacillus acidophilus. J. Food Sci. 47:2078-2079.
Kobashi, K., I. Nishizawa, and T. Yamada. 1978. A new hydrolase specific taurine-conjugates of bile acids. J. Biochem. 84:495-503.

Kritchevsky, D., and J. A. Story. 1975. In vitro binding of bile acids and bile salts. Am. J. Clin. Nutr. 28:305-306.

Mann, G. V., and A. Spoerry. 1974. Studies of a surfactant and cholesteremia in the Maasai. Am. J. Clin. Nutr. 27:464-469.

Mott, G. E., R. W. Moore, H. Redmond, and R. Reiser. 1973. Lowering of serum cholesterol by intestinal bacteria in cholesterol-fed piglets. Lipids 8:428-430.

Mozzi, F., G. S. De Giori, G. Oliver, and G. F. De Valdez. 1994. Effect of culture $\mathrm{pH}$ on the growth characteristics and polysaccharide production by Lactobacillus casei. Milchwissenschaft 49:667-669.

Nakajima, H., Y. Suzuki, H. Kaizu, and T. Hirota. 1992. Cholesterol lowering activity of ropy fermented milk. J. Food Sci. 57:13271329.

Noh, D. O., S. H. Kim, and S. E. Gilliland. 1997. Incorporation of cholesterol into the cellular membrane of Lactobacillus acidophilus ATCC 43121. J. Dairy Sci. 80:3107-3113.

Pekkanen, J., S. Linn, G. Heiss, C. M. Suchindran, A. Leon, B. M. Rifkind, and H. A. Tyroler. 1990. Ten-year mortality from cardiovascular disease in relation to cholesterol level among mean with and without pre-existing cardiovascular disease. N. Engl. J. Med. 322:1700-1707.

Sall, J., and A. Lehman, eds. 1996. JMP Start Statistics: A guide to statistics and data analysis using JMP and JMPIN software. Duxbury Press. SAS Institute. Cary, NC.

Schiff, E. R., N. C. Small, and J. M. Dietschy. 1972. Characterization of the kinetics of the passive and active transport mechanisms for bile acid absorption in the small intestine and colon of the rat. J. Clin. Invest. 51:1351-1362.

Sutherland, I. W. 1972. Bacterial exocellular polysaccharides. Pages 143-213 in Advances in Microbial Physiology. A. H. Rose and D. W. Tempest, eds. Academic Press. New York.

Tannock, G. W., A. Tangerman, A. Van Scack., and M. A. McConnell, 1989. Deconjugation of bile acids by lactobacilli in the mouse small bowel. Appl. Environ. Microbiol. 60:3419-3420.

Uemura, J., T. Itoh, T. Kaneko, and K. Noda. 1998. Chemical characterization of exocellular polysaccharide from Lactobacillus delbrueckii subsp. bulgaricus OLL1073R-1. Milchwissenschaft 53:443-446.

Vanderzant, C., and D. F. Splittstoesser, eds. 1992. Compendium of Methods for the Microbial Examination of Foods. 3rd ed. American Public Health Assoc., Inc. Washington, DC.

Walker, D. K., and S. E. Gilliland. 1993. Relationships among bile tolerance, bile salt deconjugation, and assimilation of cholesterol by Lactobacillus acidophilus. J. Dairy Sci. 76:956-961. 